\title{
MODEL OF ECO-WATER DRIVING FORCE AFFECTING THE EVOLVEMENT OF RUNOFF IN THE UPPER MINJIANG RIVER BASIN
}

\author{
JinHuang \\ WunianYang \\ Li Peng \\ Muhammad Aqeel Ashraf \\ Key Laboratory of Geoscience Spatial Information Technology, \\ Ministry of Land and Resources of the P.R. China, \\ Chengdu University of Technology, P. R. China \\ Faculty of Science and Natural Resources, University Malaysia, Malaysia
}

\begin{abstract}
The amount of eco-water resources reflects the land surface water conservation capability, and the underlying surface condition in the hydrologic cycle. In the upper Minjiang River Basin, the amounts of eco-water resources were retrieved from remotely sensed data during 1992 to 2005. Through regression analysis between the retrieved eco-water data and the climate hydrological data mainly including the temperature, the precipitation, and the runoff in the same period, the model of eco-water driving force affecting the evolvement of runoff was established. The accuracy analysis indicates that the model can well describe the relationship between dry season runoff and its driven factors, the measured data validation proves that the model has high precision and good practicability. The eco-water remote sensing inversion provides a valid method to quantify the land surface water conservation capability, and suggests an interesting approach for the driving function quantitative researches of underlying surface factor in the hydrologic cycle.
\end{abstract}

Keywords: Eco-water, Remote Sensing Quantitative Retrieval, Upper Minjiang River, Runoff Prediction

\section{INTRODUCTION}

The influence of the underlying surface change on hydrological processes should not be ignored, but difficulty of its hydrological effect quantization has been the restriction of hydrological research. Underlying surface mainly includes three layers: the vegetation canopy, vegetation humus layer and soil layer. It is usually studied through three individual experiments respectively at typical sample plots (Liu et al.1989; Ogee and Brunet 2002; Rao et al.2005; Hu et al.2014; Sun et al.2015). However this approach showed its inefficiency and low accuracy, because the sampling method often failed to describe factually and comprehensively the water storage condition of underlying surface. Hence, with the development of modern science and technology, it is desired to find a simple and effective way to discover the hydrological response to underlying surface change for the modern water science and water management.

The concept of "Eco-water (layer)" emphasizes the important role of underlying surface in hydrologic cycle. It is the extension and coupling of quantitative remote sensing to the hydrologic cycle (Yang et al. 2001; Wan et al. 2004).

Eco-water is the water closely related to the earth's land surface vegetation, forms the "eco-water layer" centered on vegetation conserved by the vegetation, the vegetation humus layer and the root soil layer after the conversion of atmospheric precipitation. Eco-water serves as a special transfer zone which differs from surface water or groundwater either in existence or in movement form. Functionally, the eco-water is capable of supplementation for both surface 
water and groundwater. Although not directly involves in the hydrological cycle processes, eco-water plays an important role of buffering and transformation in the hydrological cycle, that is the driving role of underlying surface factor.

Although subject and study methods are different, ecowater and underlying surface have the same research object (vegetation canopy, humus layer and soil layer) and research purpose (Figure1). Usually, vegetation canopy, humus layer and soil layer were researched respectively to find out that how them intercept and retain water in hydrological cycle. However, although the hydrological effect mechanism of the three is different, they have the same effect to runoff. Therefore, the overarching goal of this study was to take vegetation canopy, humus layer and soil layer as a whole by eco-water, make the effect of underlying surface on runoff quantified with the help of remote sensing technology (Li et al. 2009; Jian et al. 2012; Kyziol, L. 2013), and then build the dry season runoff prediction model from the drive angle.

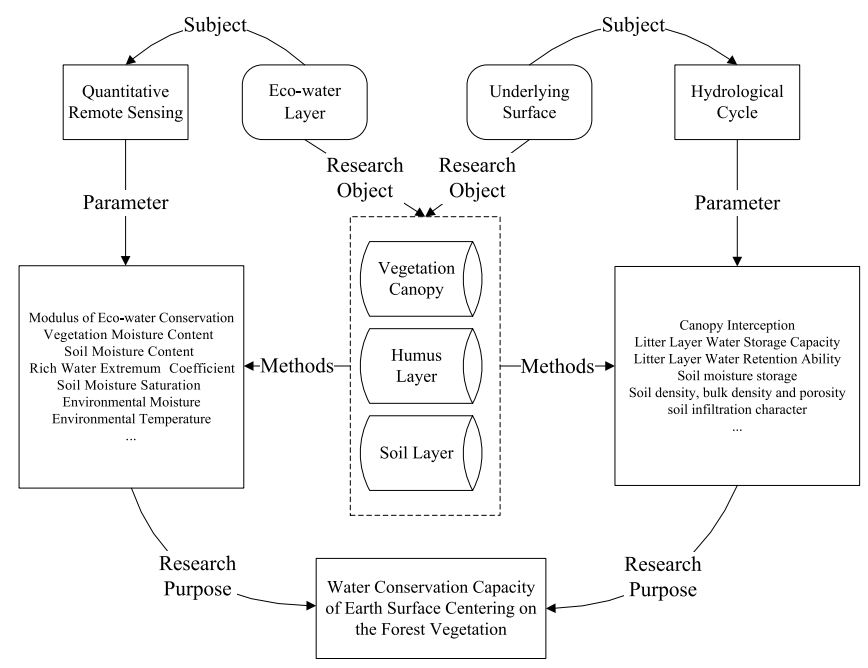

Fig. 1. The relationship of Eco-water Layer and underlying surface

\section{STUDY AREA}

The upper Minjiang River Basin, located in the transition region from eastern Qinghai-Tibet Plateau to Sichuan Basin in western China, is an essential tributary to the Upper Yangtze River and important water conservation area for the Chengdu Plain. Good or bad of the ecological environment in western regions of China directly affect the economic development of eastern China: if the western ecological environment deteriorates, water shortages, the east valley will dry up. And the diversification and multilayered of the western ecological environment, is the key to keep the normal operation of the environment in central and eastern China, is also the key to the sustainable development of China economy. The forest in the upper Minjiang River acts as the natural barrier and green reservoir of Sichuan, but due to massive deforestation for hundreds of years, the subsequent ecological environment deterioration has risen serious issues about the water conservation capacity, where the forest vegetation has decreased and thus led to observed reduction of runoff in the dry season. Thus Chinese water resources research focus on the western region, and the upper Minjiang River basin is one of the most important water resources supply basin in western China.

\section{ECO-WATER REMOTE SENSING QUANTITATIVE RETRIEVAL}

Amount of water conserved in the eco-water layer was represented by the modulus of eco-water conservation (MEC). The MEC is related to vegetation and soil water content and represents the water conservation ability of the earth's surface based on vegetation. Vegetation and soil information was extracted by remote sensing technology with high sensitivity and accessibility, thus quantification of each was a precondition for calculating the MEC. The basic research unit of remote sensing image digital processing is a single pixel with MEC following by also utilizing a single pixel as the basic research unit. According to the definition of MEC that the MEC model of pixel $(i, j)$ is as follows:

$$
\operatorname{MEC}(i, j)=\operatorname{EWTc}(i, j)+W(T)(i, j)
$$

Where $\operatorname{EWTc}(i, j)$ is vegetation water content of the pixel(i,j), $W(T)(i, j)$ is soil water content of the pixel(i,j).

If there are $\mathrm{M}$ lines and $\mathrm{N}$ rows of the remote sensing image of the study area, the amount of ecological water resource is:

$$
M E C=\sum_{i=1}^{M} \sum_{j=1}^{N} \operatorname{MEC}(i, j)
$$

The basic principle of remote sensing quantitative inversion is the reflection spectrums of surface features actually exhibit particular characteristics (Zhang et al. 2010(a)). Vegetation water content has obvious response to spectral characteristics in the wavelength range from near infrared to intermediate infrared. $1600 \mathrm{~nm}$ indicates a strong moisture absorption band while $820 \mathrm{~nm}$ indicates a weak moisture absorption band, allowing the vegetation index SR (Simple Ratio) (Equation 3) established by the ratio to effectively highlight the vegetation water content information(Zhang et al. 2010(b); Wang et al. 2011; Yi et al. 2012).

$$
\mathrm{SR}=\mathrm{R}_{1600} / \mathrm{R}_{820}
$$

Where R1600 is spectral reflectivity at $1600 \mathrm{~nm}, \mathrm{R} 820$ is spectral reflectivity at $8200 \mathrm{~nm}$. Then the measured vegetation spectral data and the measured vegetation biochemistry data were used to establish the vegetation water content model. The highest correlation coefficient model was selected from Regression analysis models (exponential, linear, logarithmic, polynomial, power):

$$
\text { EWTc }=-0.1126 \times \operatorname{Ln}(S R)+0.2974
$$

Advantages and disadvantages of soil moisture estimation models with optical sensor differ, and after analyzing the characteristics and regression effects with actual soil water 
content measurement, SMMRS (Soil Moisture Monitoring by Remote Sensing) (Equation 5) based on soil line was chosen. Soil line is a straight line in a two-dimensional spectral space of red and near infrared generated from a series of pure soil pixels ranged by reflectance. Soil line is a comprehensive reflection of the soil's characteristic in various water conditions (Zhan et al. 2007; Qin et al. 2012).

$$
S M M R S=1-\frac{1}{\sqrt{M^{2}+1}}\left(R_{645}+M R_{858}\right)
$$

Where $\mathrm{M}$ is the slope of soil line, R645 is spectral reflectivity at $645 \mathrm{~nm}, \mathrm{R} 858$ is spectral reflectivity at $858 \mathrm{~nm}$. Then the measured soil spectral data and the measured soil biochemistry data were used to establish the soil water content model, the highest correlation coefficient model was selected from Regression analysis models (exponential, linear, logarithmic, polynomial, power):

$$
\mathrm{W}(\mathrm{T})=7.7962 \times \mathrm{SMMRS}-4.7824
$$

Remote sensing data was collected from 1992 to 2005, LANDSAT images were utilized in this study. SR is the ratio of infrared wavelengths (band 5, center wavelength of 1676 $\mathrm{nm}$ ) and nearly red band (band 4, center wavelength of 840 $\mathrm{nm}$ ) in remote sensing image inversion of EWTc. The soil line of image must be derived initially to compute SMMRS for the remote sensing image inversion of $\mathrm{W}(\mathrm{T})$. The modulus of eco-water conservation of the study area was then retrieved according to the MEC model based on the already retrieved EWTc and W(T).

\section{MODEL OF ECO-WATER DRIVING FORCE AFFECTING EVOLVEMENT OF RUNOFF}

Eco-water driving force affecting the evolvement of runoff

The runoff was influenced by two of the driving factors, climate and underlying surface. The climate factors include temperature and precipitation, while the underlying surface factors are represented by vegetation. Because the factors mutual influence and restrict each other, it is hard to understand and simulate the interaction mechanism between them in order to predict the runoff more accurately (Wu et al., 2003; Sansom, 1999). It has always been the difficulties of further research in the hydrologic cycle. Precipitation, temperature, runoff data are available, but the effect of vegetation is difficult to quantify. As early as in the thirties of the 20th century, the experts and scholars had gotten the empirical relationship among hydrological characteristics, climate factors and underlying surface factors with a large amount of observation data, including vegetation type, coverage, spatial pattern and so on. But the precision of this kind of empirical relationship is difficult to guarantee. The amount of eco-water resources not only reflects the water conservation capacity of the earth's surface centered on vegetation, but also comprehensively reflects the general condition of underlying surface in the instantaneous remote sensing imaging moment. It is a final result after the interaction among climatic conditions and topography, geology, soil, vegetation, human activities, and many other factors. In the original forest, the interception of rainfall by eco-water is around $20 \%$ to $40 \%$, the interception volume should not be under estimated. In the process of hydrologic cycle, the amount of eco-water resources affects the transformation and distribution from precipitation to other kinds of water resources, and also affects the length of time of water retention in the stored body. In other words, the amount of eco-water resources represents the efficacy of reducing flood and supplying water shortage in the hydrologic cycle. From a macroscopic perspective provided by remote sensing, the hydrologic cycle driving causes analysis becomes more simple, practical and reasonable, and it is probably that the runoff prediction precision was able to be further improved.

\section{RUNOFF PREDICTION DATA}

Climate conditions during the same period should also be considered when studying the influence of ecological water on runoff. Climate data collected for this study included the precipitation and the temperature of years and months in the upper Minjiang River Basin from 1990 to 2005. The precipitation and temperature data was collected from 9 national surface meteorological stations (Songpan, Zoige, Barkam, Hongyuan, Xiaojin, Dujiangyan, Pingwu, Mianyang, Yaan) which were within or adjacent to the river basin and then were interpolated to get derive raster data of the study area. The runoff data of years and months in the Upper Minjiang River Basin from 1992 to 2005 were collected from Zipingpu hydrologic stations.

\section{MODEL OF ECO-WATER DRIVING FORCE AFFECTING THE EVOLVEMENT OF RUNOFF}

The statistical features of medium and long term runoff drive factors are relatively complicated in terms of time and space, and the practical application of factor forecast model is difficult to some extent. But, the runoff forecast model based on solid physical causes is recognized as an important development trend of the medium and long term runoff forecast. In this paper, the model of evolvement of runoff was established from driving factors of the precipitation, the temperature and the eco-water. Among the statistical empirical models, the multiple linear regression model is one of the most popular models for runoff predicting. Because the eco-water effect on runoff supplement is generally more observable in the dry season, the annual prediction depth, the annual average temperature and the eco-water depth were taken as the independent variables, and the runoff depth in dry season was taken as the dependent variable. The multiple linear regression was then carried out to establish the runoff prediction mode, modeling process as shown in figure 2 . 


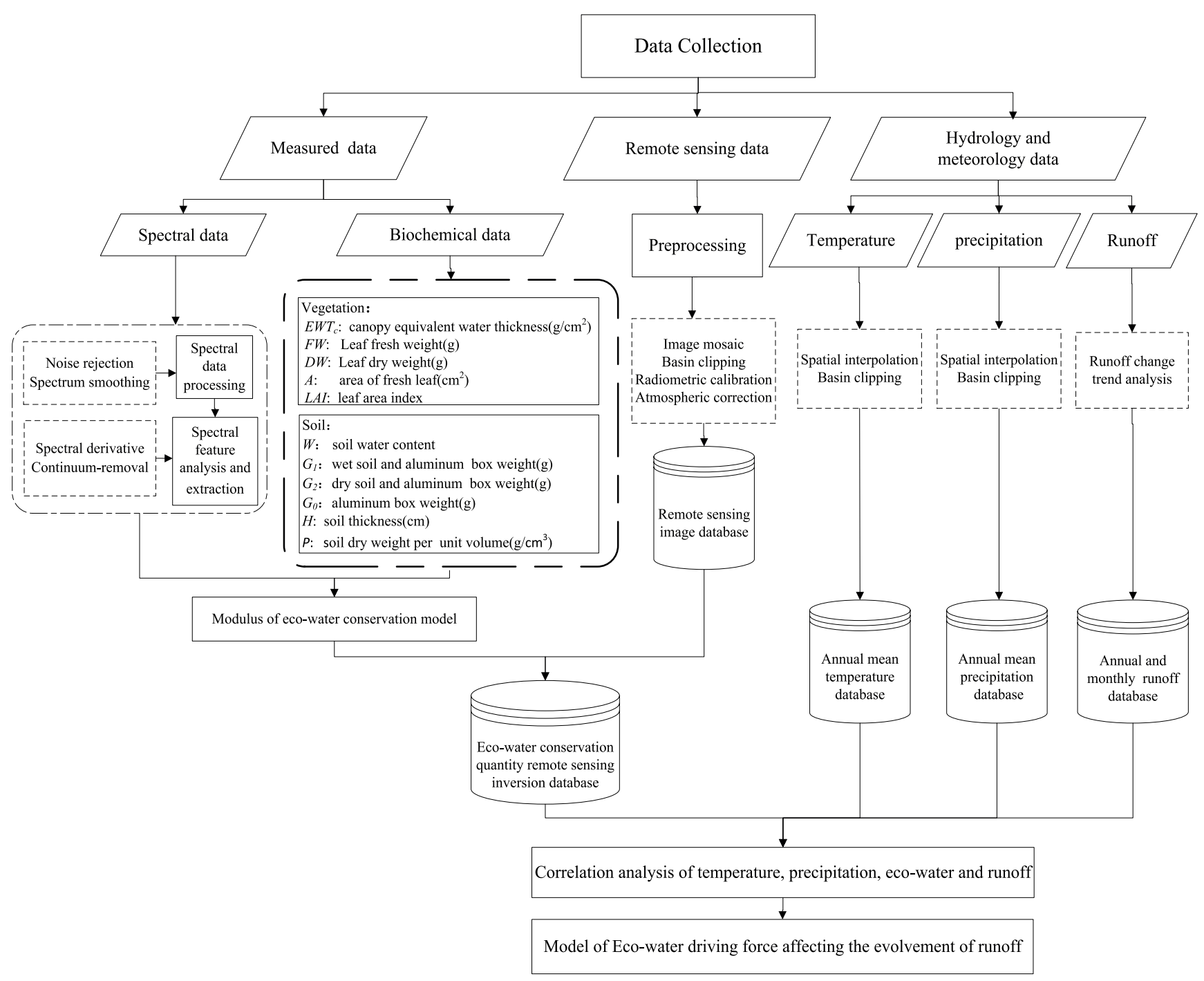

Fig. 2. Modeling flow

The mathematical model of the runoff prediction model is as follows:

$$
\mathrm{Y}=\mathrm{aX} 1+\mathrm{bX} 2+\mathrm{cX} 3+\mathrm{d}
$$

Where $\mathrm{X} 1$ is eco-water depth; $\mathrm{X} 2$ is annual precipitation; $\mathrm{X} 3$ is annual temperature; $\mathrm{a}, \mathrm{b}, \mathrm{c}, \mathrm{d}$ are undetermined coefficients. The data from 1992 to 2002 were taken as the experimental data to figure out coefficient (table 1), precision analysis and significance testing as shown in table 2 and table 3 . From precision analysis, it can be concluded that the correlation coefficient of linear regression model ( $\mathrm{r}$ ) is 0.842 and coefficient of determination $\left(\mathrm{R}^{2}\right)$ is 0.709 , which means that the model can well reflect the relationship between dry season runoff and its drive factors. From significance testing (F-test), $\mathrm{F}_{0}$ is 5.690, bigger than critical value of $\mathrm{F}_{0.05}(3,9) 3.86$, the $\mathrm{F}$ significant probability test of regression equation is 0.027 , smaller than 0.05 , mean that the linear relationship between dry season runoff and its drive factors is statistically significant by F-test.
To validate the model, three years prediction values were compared with measured values from 2003 to 2005. According to test result (Table 4), the average relative error is 0.08 , presenting a high precision and good practicability.

From significance test of single factors (table 1), probability test of eco-water is 0.006 , smaller than 0.05 , which means eco-water has significant linear relationship with dry season runoff, while probability test of annual precipitation and annual average temperature are 0.851 and 0.6345 , which means they don't have significant linear relationship with dry season runoff. For the precipitation, it is not the mainly supply for runoff yet, there is no high correlation of runoff and precipitation in dry season, as shown in figure 3, the runoff curve changes not as the precipitation in dry season. For the temperature, it has much more complicated relationship with runoff. Temperature influence on precipitation, evapotranspiration and the underlying surface pattern, and finally influence on runoff indirectly. That is why in multiple linear regression model the correlation of temperature and runoff can't be highlight. 


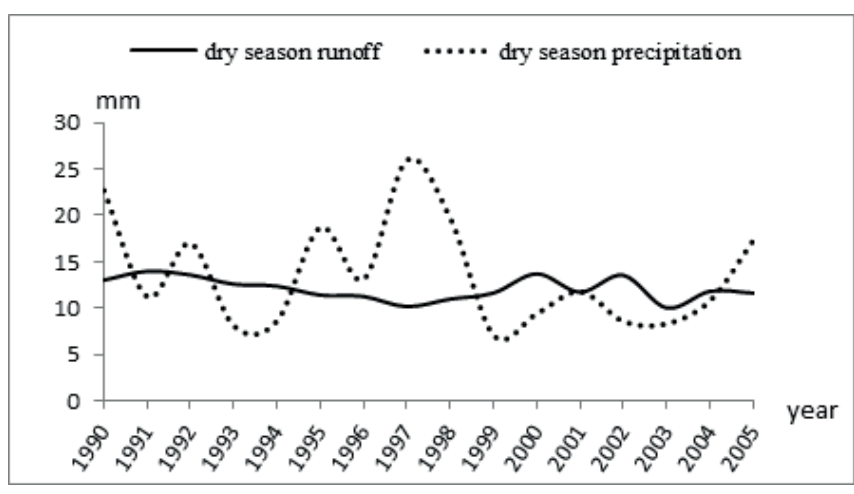

Fig. 3. Change curves of dry season runoff and precipiton

Tab. 1. Model Coefficients

\begin{tabular}{cccc}
\hline & $\begin{array}{c}\text { Unstandardized } \\
\text { Coefficients }\end{array}$ & $\begin{array}{c}\text { Standardized } \\
\text { Coefficients }\end{array}$ & Sig. \\
\hline$d$ & 6.258 & & 0.391 \\
$a$ & 0.484 & 0.812 & 0.006 \\
$b$ & 0.000 & 0.041 & 0.851 \\
$c$ & -0.268 & -0.107 & 0.634 \\
\hline
\end{tabular}

Tab. 2. Precision of linear regression model

\begin{tabular}{cccc}
\hline$r$ & $D^{2}$ & Adiusted $D^{2}$ & Std. Frror of the Fstimate \\
\hline 0.842 & 0.709 & 0.585 & 0.6464 \\
\hline
\end{tabular}

Tab. 3. Analysis of linear regression variance

\begin{tabular}{cccccc}
\hline & Sum of Squares & $\mathrm{d} f$ & Mean Square & $F$ & Sig. \\
\hline Regression & 9.686 & 3 & 3.229 & 5.690 & 0.027 \\
Residual & 3.972 & 7 & 0.567 & & \\
Total & 13.658 & 10 & & & \\
\hline
\end{tabular}

Tab. 4. Model accuracy test

\begin{tabular}{ccccc}
\hline Year & $\begin{array}{c}\text { Dry season } \\
\text { measured value }\end{array}$ & $\begin{array}{c}\text { Dry season predicted } \\
\text { value }(Y)\end{array}$ & Absolute error & Relative error \\
\hline 2003 & 10.03375 & 11.82509 & 1.791342 & 0.178532 \\
2004 & 11.8293 & 11.37945 & -0.44985 & -0.03803 \\
2005 & 11.63487 & 11.23794 & -0.39693 & -0.03412 \\
\hline
\end{tabular}

\section{CONCLUSION}

In order to solve the difficulties of underlying surface factor quantification, this paper introduces eco-water remote sensing quantitative inversion theory and method to river runoff forecast research. As the water-rich features of eco-water are special, it is difficult to make extraction and quantization with the conventional method, but quantification of underlying surface factor hydrological effect can be realized with remote sensing quantitative inversion technology. Due to eco-water research theory and technology, it is possible to reflect the water conservation function of underlying surface factor more comprehensively, macroscopically and quantitatively, thus providing strong support for researching the influence of underlying surface factor on runoff change. Taking the upper
Minjiang River Basin as the study area, this paper performs inversion of eco-water resources quantity with remote sensing method, and establishes driven runoff forecast model. The accuracy analysis shows that the model of eco-water driving force affecting the evolvement of runoff passed the test of significance and the measured data validation proves that the model has high precision and good practicability, which suggests that the influence of underlying surface on runoff quantified by eco-water is acceptable.

There are still something in need of improvement: Screening and regulating features or feature combination of drive factors sensitive to dry season runoff (such as precipitation/rainy days, the highest temperature, the lowest temperature, wind speed, humidity and so on) will be the further research; Eco-water driven factor was derived by means of quantitative remote sensing inversion. Unlike measurements such as precipitation, temperature, eco-water remote sensing inversion itself has certain accuracy error. Therefore, it is also the basis of increase runoff forecast accuracy by improving the accuracy of the eco-water remote sensing inversion advancing with the times.

\section{ACKNOWLEDGEMENTS}

Wunian Yang was sponsored by the National Natural Science Funds (NO. 41071265 and NO.41372340) and the Specialized Research Fund for the Doctoral Program of Higher Education of China (NO. 20105122110006).

\section{REFERENCES}

1. Liu, X. D., Wu, Q. X., \&Su, N. H.1989 Studies on rainfall interception in canopy, litter and soil hydrological characteristics of forests in Liupanshan mountains. Scientia Silvae Sinicae, 25(3), 220-227.

2. Kyziol, L. 2013 Stress-corrosion resistance of the EN AW-AlZn5Mg1,5CuZr alloy in different heat treatment states. Polish Maritime Research, 20(4), 39-44.

3. Ogee, J. \& Brunet, Y. 2002 A forest floor model for heat and moisture including a litter layer.Journal of Hydrology, 255(1), 212-233.

4. Rao, L.Y., Zhu, J. Z. \&BI, H. X. 2005 Hydrological effects of forest litters and soil in the Simian mountain of Chongqing city.Journal of Beijing Forestry University.27(1), 33-37.

5. Hu, X. Y., YUu, X. Y. 2014 Hydrological characteristics of litters and soil in restoration and succession of Karst forest. Guangdong Agricultural Sciences, (23), 150-154.

6. Yang, W. N., Yuan,P.X. \&Wan, X. N.2001 The study report: the ecological environment integrative survey and evaluation in the Minjiang upper river based on remote sensing, 863-308-21(6). Chengdu: Chengdu University of Technology Archives. 
7. Wan, X. N., Yang, W. N., Wu, B F., Sun, W. D. \& Huang, Q. 2004 Conception of Eco-water sphere and its application. Adv. Earth Sci, 6(19), 117-121.

8. Li, Y. X.,Yang, W. N., Tong, L., Jian, J.\&Gu, X. F. 2009 Remote sensing quantitative monitoring and analysis fuel moisture content based on spectral index. Acta Optica Sinica, 29(5), 1403-1407.

9. Jian, J., Yang, W. N., Jiang, H., Wan, X. N., Li, Y. X. \& Peng, L. 2012 A model for retrieving soil moisture saturation with Landsat remotely sensed data. International Journal of Remote Sensing, 33(14), 4553-4566.

10. Sun, B; Wei, M; Du, J; Ji, W; Wen, MQ. 2015 Multi-attribute Group Decision Making Method of Ecological Water Compensation Program Based on Preference of Decision Makers. Journal of Coastal Research, 73, 606-610.

11. Zhang, R. H., Tian J., Li Z. L., Su H. B., Chen S. H.\& Tang X. Z. 2010(a) Principles and methods for the validation of quantitative remote sensing products.Science China(Earth Sciences), 53(5), 741-751.

12. Zhang, J. H., Xu, Y., Yao, F. M., Wang, P. J., Guo, W. J., Li, L. \& Yang, L. M. 2010(b) Advances in estimation methods of vegetation water content based on optical remote sensing techniques. Science China Technological Sciences, 53(5), 1159-1167.

13. Wang, L. T., Wang, S. X., Zhou, Y., Liu, W. L. \& Wang, F. 2011 Vegetation water content retrieval and application of drought monitoring using multispectral remote sensing. Spectroscopy and Spectral Analysis, 31(10), 2804-2808.

14. Yi, Q. X., Bao, A. M., Luo, Y. \& Zhao, J. 2012 Measuring cotton water status using water-related vegetation indices at leaf and canopy levels. Journal of Arid Land, 4(3), 310-319.

15. Zhan, Z. M., Qin, Q. M., Ghulan, A. \& Wang, D. D. 2007 NIR-red spectral space based new method for soil moisture monitoring. Science in China(Series D:Earth Sciences), 50(02), 283-289.

16. Qin, Q. M., You, L., Zhao, Y., Zhao, S. H. \& Yao, Y. J. 2012 Soil line automatic identification algorithm based on two-dimensional feature space. Transactions of the CSAE, 28(3), 167-171.

17. Wu, Y., Su, Z. X. \& Fang, J. Y. 2003 Study on causes and ecological renewal of arid and warm valley of upper Minjiang river. Journal of China West Normal University(Natural Sciences), 24(3), 276-281.

18. Sansom, A. L. 1999 Upland vegetation management: the impacts of overstocking. Water Science and Technology, 39(12), 85-92.

\section{CONTACT WITH AUTHOR}

\author{
JinHuang \\ email: jinjin0522@163.com
}

WunianYang (corresponding author) email:ywn@cdut.edu.cn

Li Peng

email:pengli@cdut.edu.cn

Muhammad Aqeel Ashraf

email: ashraf@ums.edu.my

Key Laboratory of Geoscience Spatial Information Technology,

Ministry of Land and Resources of the P.R. China, Chengdu University of Technology, Chengdu,

Sichuan, 610059,

P. R. China

Faculty of Science and Natural Resources,

University Malaysia

Sabah 88400

Kota Kinabalu Sabah, Malaysia 